\title{
Teacher Talk in an EFL Classroom: A Pilot Study
}

\author{
Nana Jing \\ School of Foreign Languages and Literatures, Chongqing Normal University, Chongqing 401331, China \\ Junrui Jing \\ Department of Tourism and Pre-school Education, Chongqing Industrial Commercial School, Chongqing 402289, \\ China
}

\begin{abstract}
This study explored a non-native English teacher's teacher talk in an EFL classroom through the qualitative research methodology. The study also aimed to find out the characteristics of EFL teacher talk and to explain them. The study mainly employed video-recorded classroom data for analysis, taking classroom observation as the supplement. The study shows that teacher talk nowadays still conforms to the widely acknowledged IRF pattern, which is in line with previous studies conducted on teacher talk. The study also tries to explore the use of $\mathrm{L1}$ in EFL classroom. It shows that the EFL teacher uses Chinese mainly for three functions as explaining complex structures, ushering cultural knowledge and activating class atmosphere taking into account students' low language proficiency level; besides, non-verbal discourse is also widely displayed in EFL classroom to support the teacher talk.
\end{abstract}

Index Terms - teacher talk, EFL classroom, L1, non-verbal discourse

\section{INTRODUCTION}

According to Nunan (1991), teacher talk refers to the language used by a teacher in organizing class and language teaching. It is an essential tool for teachers in the implementation of the teaching plan and an important source of input for students. Teachers play a supporting role in classroom teaching by continuously engaging in organizing, explaining, summarizing, reformulating, and redirecting what has been said both by themselves and by students (Blanchette, 2009). The effectiveness of teaching therefore depends on the language used in classroom and the type of classroom interaction (Long \& Porrter 1985). Teacher talk must be of high quality in order to create a harmonious and effective classroom atmosphere for teacher-student interaction; otherwise, classroom teaching is prone to becoming a monodrama. In this paper, we define 'teacher talk' as the language used by the teacher in an EFL classroom from beginning to the end of the class.

\section{RESEARCH ON TEACHER TALK}

There has been a growing body of research on teacher talk at different education levels and in different subjects over the years. In line with the current research, this paper mainly summarized previous research concerning teacher talk in college English teaching after analysis of some related studies.

Sinclair and Coulthard (1975) developed a model for the description of teacher-pupil talk, based on a hierarchy of discourse units. Sinclair and Coulthard (cited in McCarthy, 1991) do agree that there does exist a structure, which means teacher talk is not at random. And McCarthy (1991) summarizes it as the TPT model, where the three initials represent Ask-Answer-Comment respectively and the TPT model as a whole is called an exchange. Many investigations have shown that more than $50 \%$ of exchanges between teacher and students are of the IRF pattern (Cazden, 1986; Edwards \& Mercer, 1987; Wells, 1999, cited in Viiri, 2006), where I refer to the initiation of the dialogue by the teacher, normally with a question; $\mathrm{R}$ is the student's response; and $\mathrm{F}$ is the feedback from the teacher.

Blanchette (2009) points out that in traditional, teacher-centered classes, teachers are liable to dominate the interaction at different education levels. As time goes by, studies have shown that teacher-controlled classroom is partially replaced, where the communicative model more closely resembles the apparently unstructured natural conversation outside the classroom. The structured exchange differs from that of the traditional classroom model in that students take more initiative in turn-taking, in request clarification and others. However, it is not the case in Chinese EFL English classroom, even in universities, some teachers still seem to control and direct the classroom as before.

Forman (2012) points out that though there is ample literature concerning teacher talk itself, until recently relatively little attention has been paid to the role of L1 in L2 education, particularly in the EFL classrooms. Forman (2012) focused on the role of L1 in L2 pedagogy and analyzed six functions of bilingual EFL teacher talk: animating, translating, explaining, creating, prompting and dialoguing. To sum up, there remain very few empirical studies concerning actual teacher talk in such contexts, which is also the case in our EFL classroom.

When it comes to teacher talk in English teaching in China, a series of research have been carried out in English major teaching classes (Feng 2007, Wu 2007, Wang 2012, Zhu 2014). Feng (2007) has investigated and analyzed discourse types, proportion of teacher talk, methods of feedback and error correction of teachers in intensive English 
reading class through recording and questionnaires. Research shows that students have high expectation and dependency for teacher's in-class talk and teachers' talk in intensive English reading classroom bears the typical characteristics of communicating information. Based on the theory of language input hypothesis, interaction hypothesis and language output hypothesis, Chen (2014) carries out a qualitative and quantitative study by analyzing recordings of the three teacher's teacher talk in the classroom from types of teachers' utterances, types of teachers' questions, questioning strategies, meaning consultation and feedback.

Comparatively speaking, studies of teacher talk in non-English major teaching classes are sparse (Li 2008, Wang 2012, Lü \& Wang 2013, etc.). Li (2008) analyzed the discourse of non-English classes from four aspects: the total proportion of teacher talk, questioning, feedback and error correction, and pointed out that teacher talk within the class bears strong interactive features. Wang (2012) did similar study concerning the above mentioned aspects by recording a 50-minute oral English class and asking students to evaluate the teacher discourse-related content. It is pointed out that the teacher's discourse plays a decisive role in oral English classroom learning, and group discussion can promote oral English learning more effectively. Lü \& Wang (2013) used classroom observation, questionnaire survey and other methods to quantitatively analyze the characteristics of the teachers in the college English classroom based on the digital resources platform, pointing out that the digital resources platform can effectively support the teaching, enhance the learners' understanding of the teacher talk and promote the meaning negotiation between teachers and students.

Taking into consideration the discussions above, it is clear that teacher talk in non-English major teaching classes has not been given enough consideration; on the other hand, the role that L1 plays in students' language learning has not been given focus. In light of these, this study focuses on a non-native teacher's classroom practices in the non-English major students' teaching class and the aim is to explore an EFL teacher's talk in her classroom practices mainly through classroom observation and recorded data analysis.

\section{THE STUDY}

\section{A. Context and Participants}

The study was conducted in a university in Chongqing. The teacher volunteered to participate in the study, and data used in this study were collected through the classroom observations during natural teaching. Firstly, the teacher was assigned a pseudonym as Jane for the confidentiality. Since getting M.A, she had been teaching English at the same university at the time of data collection. She had three different sophomore classes consisting of 45 to 60 students. In the lesson presented for analysis, she followed the course-book, that is, she still continued the teaching of reading text of unit one and the topic was on experience of first love. Due to students' English proficiency level (students passing CET-4 have the right to opt whether to attend the English class), she mainly employed grammar translation method for the lecture and she tried best to motivate students and to involve students in thinking and to raising questions.

\section{B. Research Questions}

The focus of this study is teacher talk in EFL classroom. We will be particularly interested in the following research questions:

1. Does the question-answer sequence between the teacher and students conform to a certain internal structure or is it just a string of language forms?

2. Does L1 play a role in such classroom since it is a shared language of both the teacher and students? If so, how to account for it?

3. If teacher talk fails, what are there to compensate?

\section{Data Collection}

This study mainly adopted a qualitative and descriptive case-study approach to investigate the EFL teacher talk and it mainly employed video-recorded real classroom data for analysis. The lesson is directed at non-English major sophomores and it lasted for 45 minutes.

\section{ANALYSIS OF DATA}

Description and analysis of teacher talk in a natural EFL classroom setting is the focus of the current study, so the videoed lesson is transcribed. $\mathrm{T}$ in the transcribed data refers to teacher, $\mathrm{S}$ refers to any student who speaks, and numbered S like S1 refers to a typical student who speaks while SS refers to the situation where more than one student speaks. Pinyin will be used to indicate Chinese in the script. The analysis will answer the above mentioned research questions in sequence.

\section{A. IRF Pattern}

As is mentioned in the previous part in IRF, I refer to the initiation of the dialogue by the teacher, normally with a question; $\mathrm{R}$ is the student's response; and $\mathrm{F}$ is the feedback from the teacher. The whole class lasts for 45 minutes, and it comes into three stages of greeting, revision and lecture, of which lecture is the major part. This is a reading class and question-answer composes a larger part of class time and the IRF pattern runs through the whole class, which conforms to previous studies concerning teacher talk in the part of question-answer, but carries more in that the IRF also appears 
in the greeting, as are shown in fragments (1) and (2). Fragment (1) is the greeting before class begins, which indicates a simple teacher-student interaction. Fragment (2) appears around the time point of 4'41" when the teacher just begins the class lecture of a sentence in paragraph 2: I hate compulsory education with a passion. While students are not unfamiliar with the notion of compulsory education in Chinese, the teacher tries to get through this notion to students in English. All the facts above help to illustrate that classroom teacher talk is still a dominant activity in the EFL classroom and teacher talk is not at random, rather, it follows the basic triadic pattern of teacher question, student answer, and teacher evaluation. In addition, the pattern of this triadic dialogue was largely restricted to recalled information given in the form of single-word answers, which was supported in Wilson (1999).

(1) T: Good morning, everyone.

SS: Good morning, Miss.

T: Today, we continue to learn the reading text of Unit 1, please turn to page 2.

(2) T:Yiwu jiaoyu means you have to go to school when you are 5 or 6 years old. But the reality is, Okay, try to understand me.

$\mathrm{T}$ : In some places, in some villages, do you know village?

SS: Cunzhuang. remote?

$\mathrm{T}$ : In some villages, especially in some remote (the word is written on blackboard) villages. Do you know

SS: Yaoyuande.

T: Yes, faraway.

T: So especially in some remote villages, actually the children have no right to go to school, do you understand? SS: Yes

T: because sometimes there is no school and there are no teachers and they have no money. Do you understand? SS: Yeah.

\section{B. Code-switching}

Concerning the way teacher talk is expressed, half of it is in Chinese. Chinese as L1 for the students and the teacher herself in this class is mainly used for three functions: to explain grammar, to usher cultural knowledge and to activate classroom atmosphere. The teacher uses Chinese when she is trying to help students to analyze the sentences like Debbie would catch me staring at her, and she would flash a smile that radiated intelligence and quickened my heartbeat. Here the structures catch me staring and a smile that ....as complement structure and attributive clause respectively are a bit hard for students, so the teacher chooses Chinese for clear explanation. Since the topic is first love and Cupid appears in paragraph, the sentence Cupid aimed his arrow and struck me right in the heart is not that hard for students to understand and translate. In order to provide the students with some cultural background information, the teacher supplements the text with an introduction to Cupid and the English name (in Roman mythology) of the nine planets in universe, whose Chinese names are familiar to students. The teacher also invites students' response to the question: what does the author mean by saying flash a smile that radiated intelligence. The whole explanation lasts around 10 minutes. Of course, English reading is always deemed as quite difficult and boring for many students. In order to activate the class atmosphere and to help students to concentrate, the teacher uses humorous Chinese to explain to students the actual situation embodied in the following sentence: My princess sat near the pencil sharpener, and that year I ground up enough pencils to fuel a campfire.... We were separated not only by five rows of desks, but by about 50 I.Q. points. In this part of the story, even though there is a distance between them in space, the boy tries his best to make full use of opportunities to be nearer to the girl, especially the opportunity of sharpening the pencil.

\section{Non-verbal Discourse}

Though we narrow down teacher talk in this paper, the function of non-verbal discourse cannot be ignored. Non-verbal discourse mainly refers to the body language that goes together with teacher talk. In this video reading class, the teacher tries to combine many forms of non-verbal discourse such as eye-contact, facial expression, body gestures, etc. To be more specific, even though the students hesitate to answer questions, especially difficult ones, the teacher wears an encouraging smile from the beginning to the end and tries to use gestures to help students understand the meaning. For example, in the sentence that year I ground up enough pencils to fuel a campfire. ...the teacher uses the pointing gesture to the ground and then an upward gesture to indicate the meaning of ground up. The teacher also employs a nodding head and affirmative eye-contact throughout the lecture.

\section{EXPLANATION FOR THE ANALYSIS}

\section{A. Explanation for IRF Pattern}

During this 45-minute class, the teacher talks for most of the time, except for the fact that she also asks 8 students to either answer short questions or translate short sentences. The students themselves voluntarily pose questions only twice, and the questions are all about certain word meaning; to be more specific, meaning of the words occasionally and intelligence are asked by two students when the teacher says that she is going to ask someone to answer questions. The IRF patterns happens roughly 29 times, which are characterized by short questions and quick answers. For example, the 
teacher will ask students for the meaning of phrasal gaze at; when the students answer with Chinese 'ningshi', the teacher supplements with a short comment and complement yes, stare at. We can see that the teacher controls the classroom and the whole teaching proceeding, which may find some explanations in the theory of critical discourse analysis.

Discourse analysis emphasizes the research method of close observation of people communicating in natural settings and the various disciplines that feed into discourse analysis have shared a common interest in language in use, in how real people use real language, as opposed to studying artificially created sentences (McCarthy, 2001). In traditional classrooms, the teacher usually takes initiative in talking and controls the talking time, which can be seen as a symbol of power control over class and students. However, it is still the case in some college English classrooms. As is seen in this typical English reading class, teacher talk occupies the majority of time, which can be explained in many aspects. Concerning students, maybe they are deficient in English language or they are not clear about the teacher's questions or they are just reluctant to ask or answer questions even though they understand what the teacher is talking about; that is to say, some students still resist assuming responsibility for taking a more active role in classroom interaction due to their personal habit, personality, lack of knowledge, lack of confidence and others. In order for the class teaching to go smoothly, the teacher still has to take the role in organizing activities, in asking questions, in eliciting participation and anticipating questions, which goes in line with Wells 1993(cited in Blanchette, 2009). As far as the teacher is concerned, maybe she lacks teaching experience in how to motivate students or she is not accustomed to classroom silence. However, it may also reflect the status quo in some college English classrooms: teachers and students are still distanced.

\section{B. Explanation for Code-switching}

Cameron \& Larsen-Freeman (2013) proposes the complex system. In language teaching, Cameron \& Larsen-Freeman (2013) points out that although language in syllabus and textbook is frozen and stabilized, it immediately becomes dynamic once coming into the classroom practice. Language class is characterized by the process of continuous interactive adjustment and adaption between teacher-student, student-student, and teacher-textbook. Therefore, we can understand that teacher talk is not something stable and unchangeable and English class is not always conducted in total English; sometimes, mother tongue must be involved for clarity, for better understanding of the lecture, or even for activating classroom atmosphere and some other factors. In this English reading class, the teacher employs mother tongue, Chinese in this current context, mainly for clear explanation, for appreciation of the description and for activating the classroom atmosphere. For example, the students are quite strange to the western mythology of Cupid story and other gods. For better understanding of meaning, the teacher must also switch to Chinese for a while. For example, when the teacher tries to explain how the boy tries to capture attention of the fancy girl, it is not enough by only telling the students the boy always goes to the pencil sharpener. The teacher must try to reproduce the real scene. To sum up, the use of L1 still exists in college EFL classrooms, which is not only the case in this English reading class, but also true in some other English classrooms for L2 students. The use of L1 helps paraphrase and exemplification of meaning and cultural information to cater for students' proficiency level.

\section{Explanation for Non-verbal Discourse ${ }^{l}$}

There are two main channels of human communication: verbal and nonverbal. As the name implies, non-verbal communication is issued by the human body with a set of image or symbols, including human facial expressions, changes in posture, body movements and body position (Zhou \& Li, 1997). American communicator Mehabian (1981) ${ }^{2}$ has also argued that meaning of a message is communicated by words, tone of voice and body language, among which body language occupies 55\%. Though the statement is open to later arguments and debates, it does indicate that body language is important in communication. Non-verbal communication acts as an important way to compensate for and assist verbal communication in walks of social life. On basis of typical example analysis from literal works and daily life, $\mathrm{Hu}$ (2002) argues that body language mainly embodies the following types of functions: the function of expression, the function of cognition, the function of indication, the function of imitation, the function of ceremony and propriety, the function of replacement, the function of show or cover and the function of suggestion, which offers helpful hints for communication.

Non-verbal communication has also been widely used in classroom and its effects have been proved by many researchers through experimental or empirical evidence. For example, teachers can employ non-verbal communications to clarify the expression of meaning so as to well deliver message, to promote interpersonal relationship between the teacher and students by shortening the distance between, which eases the atmosphere, and even to reveal the teacher's own character. As we have mentioned in the previous part, this teacher in the videoed class takes dominance in classroom due to the fact that she does most of the talking. However, it does not mean that she is the boss and students are in a submissive and silent situation. Instead, the teacher makes gestures and smiling facial expression to express meaning and to encourage students to get involved in class; the students themselves also keep interacting and discussing even though they may not have an answer for a typical question, which makes the classroom atmosphere still a relaxed

\footnotetext{
${ }^{1}$ Here in our paper, non-verbal communication, nonverbal discourse and body language are used interchangeably despite their distinctions.

${ }^{2} \mathrm{https}$ //www.businessballs.com/communication-skills/mehrabians-communication-theory-verbal-non-verbal-body-language-152/ (Professor Albert

Mehrabian's communications model)
} 
one.

\section{CONCLUSION}

In this study, we focus on the teacher talk of an EFL teacher by classroom observation and analyzing the video-recorded classroom data. The findings show that teacher talk nowadays still conforms to the widely acknowledged IRF pattern, which is in line with previous studies conducted on teachers talk, however, one thing worthy our notice is that the feedback part is sometimes omitted when the first round of IRF is followed by a second round or when feedback is not so necessary.

The study also tries to explore the use of L1 in EFL classroom. It shows that Chinese still takes an important in EFL classroom and in the current case, the teacher uses Chinese mainly for three functions like explaining complex structures, ushering cultural knowledge and activating class atmosphere taking into account students' proficiency level. In order to further convey meaning, the teacher also employs certain non-verbal language such as body gestures and positive facial expressions throughout the classroom, which to a certain extent, weakens the dominating tendency of absolute teacher talk.

In this study, only a 45-min class is analyzed (part of the reading text), to better explore and understand teacher talk in EFL classrooms, it is good to collect data from classes from other teachers and also in other types of classes, like listening, speaking and writing. Length of time is also to be considered. The study is also confined in research methodology. Although class observation and natural classroom tape-recording are a good start, they should be developed more full in future studies.

\section{ACKNOWLEDGEMENTS}

The project partially described in this paper is supported by a grant college of foreign languages and literatures, Chongqing Normal University (2015wy007). I am indebted to the teachers who participated in this project and who continue to work on their English teaching to guarantee the objectivity.

\section{REFERENCES}

[1] Blanchette, J. (2009). Characteristics of teacher talk and learner talk in the online learning environment. Language and Education 23.5, 391-407.

[2] Cameron, L\&Larsen-Freeman, D. (2013). Complex systems and applied linguistics. Shanghai: Shanghai Foreign Language Education Press.

[3] Chen, S. G. (2014). An analysis of teacher talk in the integrated English class for the first-year college English majors. M.A. thesis, Capital Normal University.

[4] Feng, Q. (2007). A study on teacher talk in intensive reading class of English majors. M.A. thesis, Central China Normal University.

[5] Forman, S. R (2012). 'Six functions of bilingual EFL teacher talk: Animating, translating, explaining, creating, promoting and dialoguing'. RELC journal 43.2, 239-253.

[6] Hu, D.Q (2002). On functions of body language, Foreign Languages and Their Teaching 12, 11-14.

[7] Li, S.S. (2008).A study on the teacher talk in college EFL classroom. M.A. thesis, Northeast Normal University.

[8] Long, M.H.\& P.A.Porrter. (1985). Group work, interlanguage talk and second language acquisition. TESOL Quarterly19.2, 207- 227.

[9] Lü, T. T \& Wang, Y.C. (2013). An empirical study on teacher talk in college English classroom: Based on teaching resource platform. Foreign Languages in China.4, 69-77.

[10] McCarthy, M. (1991). Discourse analysis for language teachers. Cambridge: Cambridge University press.

[11] Nunan, D. (1991). Language teaching methodology: A textbook for English teachers. London: Prentice Hall.

[12] Viiri,J. \&Sarri, H.(2006).Teacher talk patterns in science lessons: Use in teacher education. Journal of Science Teacher Education 17, 347-365.

[13] Wang, Z. P.(2012). Case study of teacher talk in EFL classroom. Journal of Jiangxi University of Science and Technology 2, 90-93.

[14] Wu, D.N. (2007). A study of gender differences of English teacher talk. Journal of Jixi University 6, 68-70.

[15] Zhou, G.G \&Li, X.N, etc. (1997). Body language. Beijing: Minzu University of China Press.

[16] Zhu, L. (2014). Analysis of attitude in teacher talk in EFL classroom. M.A. thesis, Zhejiang University.

Nana Jing received her master degree in linguistics from Guangdong University of Foreign Studies in 2013. She is currently lecturer on College of Foreign Languages and Literatures, Chongqing Normal University, Chongqing, China. Her main research interest is syntax and language education.

Junrui Jing is currently a teacher in Chongqing Industrial Commercial School, Chongqing, China. His main research interest is translation and language education. 